\title{
Socio-economic factors associated with the purchasing of insecticide-treated nets in Afghanistan and their implications for social marketing
}

\author{
Natasha Howard',2, Daniel Chandramohan', Tim Freeman', Ahmed Shafi', \\ Mohammed Rafi', Sayed Enayatullah' and Mark Rowland ${ }^{1,2}$ \\ 1 HealthNet International, University Town, Peshawar, Pakistan \\ 2 London School of Hygiene and Tropical Medicine, London, UK
}

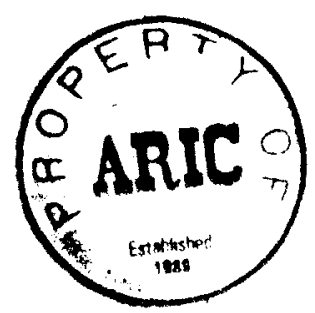

Summary Malaria is often a major health problem in war-torn countries in the tropics owing to the collapse of health services and the vulnerability of displaced populations to epidemics. Insecticide-treated nets (ITN) represent one of the few options for obtaining protection against malaria in unstable settings deficient in health infrastructure. Social marketing of subsidized ITN by a consortium of non-governmental organizations began in Afghanistan in 1993 and has continued every year since then despite regular political turmoil. Almost 350000 nets have been sold and approximately 1.2 million people protected. In 2000 we examined the determinants of ITN purchasing among households in Nangarhar province, eastern Afghanistan, as part of an effort to increase ITN uptake. The survey was conducted using a structured questionnaire to collect data on socio-economic characteristics and malaria beliefs and practices among more than 400 net-owning and non-net-owning households. A composite socioeconomic index was created using principal components analysis, and survey households were divided into socio-economic quartiles. ITN were 4.5 times more likely to be purchased by families from the richest quartile and 2.3 times more likely to be purchased from the upper-middle quartile than from the two lower quartiles. Even so, a significant minority from the lower quartiles did prioritize and buy ITN. In conflict affected countries where livelihoods are compromised, it is necessary to target subsidies at the most impoverished to make ITN affordable and to improve overall coverage.

keywords insecticide treated nets, social marketing, malaria, refugees, conflict, Afghanistan, complex emergencies

\section{Introduction}

Malaria is a major cause of morbidity and mortality in tropical countries affected by conflict (Rowland \& Nosten 2001). During the acute phase of the crisis, when populations may be forced to evacuate conflict zones, mortality rates because of malaria may grow alarmingly (Toole \& Waldman 1997). Quick and simple humanitarian interventions that reduce human-vector contact may provide temporary respite. These interventions may include tents (Hewitt et al. 1995; Bouma et al. 1996), blankets (Rowland et al. 1999; Graham et al. 2002a) and polyethylene tarpaulin shelters (Graham et al. 2002b) that have been treated with insecticide. Insecticide-treated nets (ITN) may also be useful although evidence is accumulating that ITN have more potential in post-emergency or chronic conflict conditions (Rowland \& Nosten 2001; Rowland et al. 2002; Kolaczinski \& Webster 2003). In settled communities there is overwhelming evidence that ITN can achieve much in alleviating the burden of malaria (Abdulla et al. 2001; Guyatt et al. 2002). Donor-supported ITN distribution programmes increasingly use a social marketing approach, and to encourage sustainability may involve local non-governmental organizations (NGOs) and the private sector to sell nets and insecticide (Chavasse et al. 1999).

Owing to the breakdown of public health infrastructure and conflict-induced population displacements, malaria has become a major health problem in many areas of Afghanistan over the last 20 years (Rowland et al. 2002a). From 1993 to the present day ITN have been widely promoted in more stable areas of eastern and southern Afghanistan, and in refugee settlements in Pakistan, through a group of NGOs coordinated by HealthNet International (HNI). The HNI programme has sold more than 350000 family-size ITN, covering about 1.2 million people or $30 \%$ of the eastern population (Rowland $e t a l$. $2002 \mathrm{~b}$ ). This level of coverage, while being beneficial to 
users of nets, is insufficient to eliminate malaria as a public health problem. Previous studies have addressed ITN acceptability and efficacy in the region (Rowland et al. 1996, 1997, 2002b; Webster et al. 2003) but little is known about the socio-economic determinants of buying nets in chronic emergency situations and their effects upon coverage and public health impact.

\section{Methods}

\section{Study area}

Malaria in Afghanistan is seasonal, hypoendemic, and prevalent in irrigated lowland areas. Outbreaks are regularly reported in areas deficient in health services or subject to population displacements. The annual transmission cycle shows a peak in spring because of Plasmodium vivax and a peak in summer-autumn because of both $P$. vivax and $P$. falciparum. Major vectors include Anopheles stephensi, A. culicifacies and A. superpictus (Dhir \& Rahim 1957; Rowland et al. 2002a). The malaria problem has grown worse during the war, and prevalence is now higher than it was in the 1950s before the establishment of the national malaria control programme (Rowland et al. 2002a). In particular $P$. falciparum has become much more prevalent because of chloroquine resistance (Shah et al. 1997; Rab et al. 2001). In Nangahar province, the site of the present study, major conflict ceased in 1992 and many refugees returned from Pakistan to rebuild homes and lives.

\section{Social marketing}

Social marketing of ITN started in 1993, 1 year after the completion of an efficacy study in Afghan refugee camps in Pakistan which demonstrated the effectiveness of ITN (Rowland et al. 1996). The first sales outlets were 40 clinics run by $15 \mathrm{NGO}$ in several districts in the eastern provinces of Nangahar, Kunar and Laghman. A year later, mobile teams of health educators and salesmen began selling ITN in more remote villages beyond the clinic catchment areas. Demand for ITN grew, and by 1999, 141018 family nets (each covering an average of 3.5 individuals) had been sold in the three eastern provinces. In some areas, particularly around the city of Jalalabad where sales campaigns were more intense, up to $60 \%$ of the local population acquired ITN (Rowland et al. 2002). The price of nets had to be reset each year, owing to inflation, but averaged around $\$ 3$ per net. This amounted to a one-third subsidy on the procurement price. Mobile teams offered an insecticide re-treatment service each spring at a charge of $\$ 0.05$ per net. Sales revenue went into a revolving fund to procure further nets. The nets were made of knitted polyester and imported from a Southeast Asian manufacturer. Prior to the social marketing project, net usage in Afghanistan was very limited; $<2 \%$ in most areas (Rowland et al. 1996).

\section{Socio-economic survey}

The survey was conducted from July to September 2000 in the eastern province of Nangarhar. Household assets and socio-economic indicators, identified in a preliminary survey and from published literature (Lariosa 1986; Ongore et al. 1989; Rashed et al. 1999), formed the basis for a structured questionnaire that was translated into the local Pashtu language. Household interviews were conducted by five local field workers. Twenty-one villages from eight districts were randomly selected from a list of villages that had been previously targeted with bed nets by HNI. Districts were purposefully selected to include some that had been subjected to regular sales campaigns and others further away from the provincial capital that had been targeted less frequently (Fig. 1). Households were randomly selected in these villages using a directional numbering system in which the interviewers, on leaving the house of the village head, asked any child to choose a number between 1 and 4 and proceeded to the second house in the direction thus selected and conducted an interview if the household was eligible. To be eligible a household had to consist minimally of husband, wife and a child under 12 years of age. Interviewers were given a daily target of eight to 24 households depending on village size, and instructed to select equal numbers of net-owning and non-net-owning households. This method was chosen for its simplicity and because no village census data or maps were available.

A socio-economic index was created using Principal Components Analysis (PCA) (Armitage \& Berry 1987). This method has been shown to effectively measure economic status based on household asset indicators without the necessity of direct income or expenditure information (Filmer \& Pritchett 1998, 1999). The socioeconomic index of households $\left(A_{\mathrm{h}}\right)$ was calculated using the following PCA model: $A_{\mathrm{h}}=\sum F_{n}\left(A_{n j}-A_{n}\right) /\left(S_{n}\right)$, where $F_{n}$ is the 'scoring factor' of $n^{\text {th }}$ asset, $A_{j n}$ is the PCA score for $n^{\text {th }}$ asset of $j^{\text {th }}$ household, $A_{n}$ and $S_{n}$ are the mean and standard deviation of the PCA score for $n^{\text {th }}$ asset. The final PCA model was based on 24 asset variables that: (i) showed a significant association with ITN ownership $(P<0.05)$; (ii) were identified a priori from the preliminary study or from key informants.

All variables fitted into the model and their scoring factors are shown in the Appendix 1. Each household was 
Figure I Province of Nangahar, Afghanistan, and study districts (shaded).

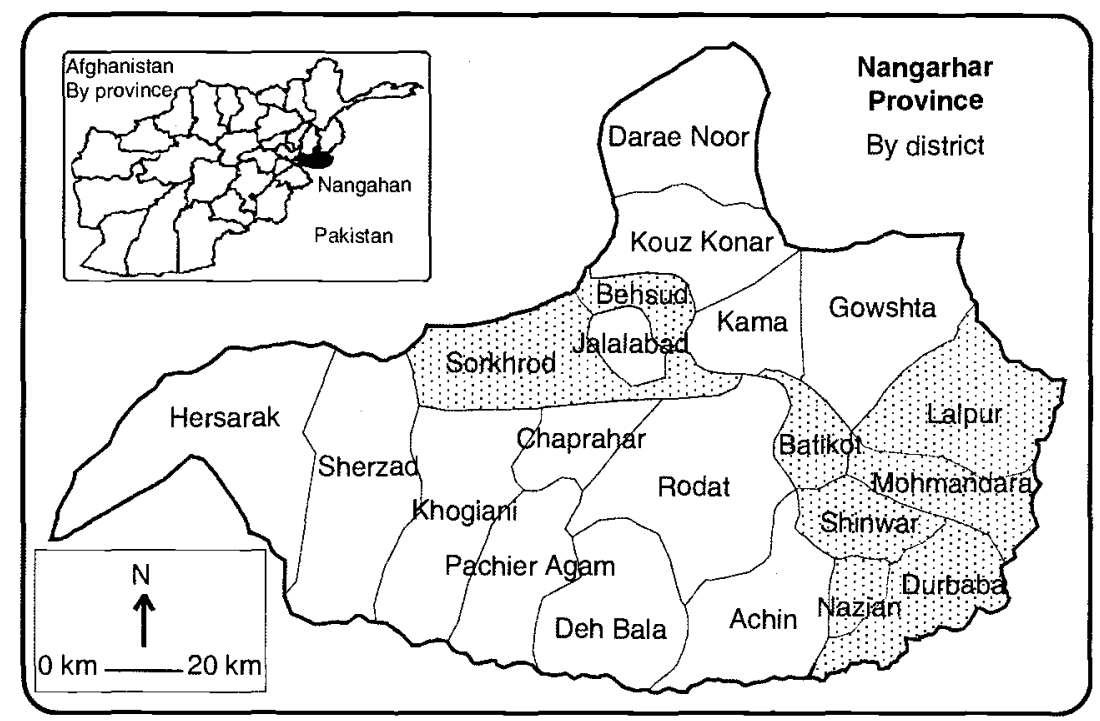

assigned to a socio-economic quartile according to PCA score. The association between socio-economic index and bed net ownership was estimated by fitting a logistic regression model that included a variable adjusting for the effect of possible variation between study districts.

\section{Results}

The response rate of the selected households was $95 \%$; a small minority was not accessed because of the absence of elder males. Data were gathered from 200 ITN owners and 214 non-owners. Because ITN coverage rates differed between districts (Table 1 ) relatively fewer net-owning families were identified and interviewed in the districts furthest from Jalalabad, namely Lalpur, Durbaba and Mohmandara (total of 42 ITN owning, 82 non owning

Table I Insecticide-treated nets (ITN) coverage in the study districts. ITN data was obtained from the social marketing records of HNI (1993-1999). Population data was based on census data and repatriation data of UNIDATA and UNHCR. The calculation of coverage assumes three individuals per family-size net, obtained from an earlier ITN efficacy trial (Rowland et al. 1996)

\begin{tabular}{lrrl}
\hline District & Population & ITN sold & Coverage (\%) \\
\cline { 1 - 2 } Behsud & 75404 & 12214 & 50 \\
Surkhrod & 118294 & 12564 & 33 \\
Batikot & 59983 & 3691 & 19 \\
Shinwar & 37647 & 5959 & 49 \\
Nazian & 8557 & 2060 & 74 \\
Momandara & 35237 & 2804 & 24 \\
Lalpur & 16093 & 649 & 12 \\
Durbaba & 27379 & 162 & 2 \\
\hline
\end{tabular}

families). Whereas in districts neighbouring Jalalabad, namely Sorkhrod and Behsud, the reverse was the case (82 ITN owning and 57 non-owning families). In other districts (Batikot, Shinwar and Nazian) almost equal numbers of each group were selected (76 ITN owning and 75 nonowning families). Most households belonged to the Pashtun ethnic group while about 150 households, mostly in Behsud district, were of Tajik ethnicity. The distribution of selected socio-economic indicators and other characteristics of bed net owners and non-owners are shown in Table 2. Heads of households that owned nets were significantly more likely to have a job other than farming and to be better educated than heads who did not own nets. Net owners were also more likely to have electricity, and to own fans, wells and pressure cookers. Net owners were more likely to own land, lease out land, to employ labour and to have cash savings. Members of households that did not own nets were more likely to work as labourers for landowners and to have household items on credit.

The socio-economic index derived from PCA ranged from -3.4 to 11.4 : the poorest quartile ranged from -3.4 to -1.29 , lower-middle quartile from -1.28 to -0.36 , upper-middle from -0.35 to 0.85 and the richest quartile from 0.86 to 11.4 . The distribution of assets in households in the four socio-economic quartiles is shown in Table 3. The distribution of assets included in the PCA model correlated closely with the four socio-economic quartiles with the exception of spare income, number of sources of income and mean area of land rented.

There was a clear trend in the association between net ownership and socio-economic index (Table 4). Net owners were three times more likely to belong to the 
N. Howard et al. Socio-economic factors associated with the purchasing of insecticide-treated nets

Table 2 Comparison of socio-economic indicators and other selected characteristics between bed net owners and non-owners

\begin{tabular}{|c|c|c|}
\hline $\begin{array}{l}\text { Socio-economic } \\
\text { indicators }\end{array}$ & $\begin{array}{l}\text { Non-owners of } \\
\text { nets }(214) n(\%)\end{array}$ & $\begin{array}{l}\text { Net owners } \\
(200) n(\%)\end{array}$ \\
\hline \multicolumn{3}{|l|}{ Household head's job } \\
\hline Farmer & $141(66)$ & $98(49) * *$ \\
\hline Other & (25) & $82(41)$ \\
\hline Unemployed & $19(9)$ & $20(10)$ \\
\hline $\begin{array}{l}\text { Household head's mean } \\
\text { age (years) }\end{array}$ & 45.1 & 44.3 \\
\hline \multicolumn{3}{|l|}{ Houshold head's education } \\
\hline None & $144(67)$ & $93(47)$ \\
\hline Primary school & $13(6)$ & $15(8)$ \\
\hline Secondary school & $23(11)$ & $29(15)^{*}$ \\
\hline Higher & $34(16)$ & $63(32)^{* n+x}$ \\
\hline \multicolumn{3}{|l|}{ Source of incomet } \\
\hline Wages & $156(73)$ & $138(69)$ \\
\hline Crops & $89(42)$ & $95(48)$ \\
\hline Regular salaries & $14(7)$ & $23(12)$ \\
\hline Rents & $8(4)$ & $7(4)$ \\
\hline Animals & $4(2)$ & $3(2)$ \\
\hline Donations & $6(3)$ & $1(-)$ \\
\hline \multicolumn{3}{|l|}{ Houset } \\
\hline House owned & $154(72)$ & $158(79)$ \\
\hline Guest room present & $107(50)$ & $131(66)$ \\
\hline Rooms carpeted & $76(36)$ & $107(54)$ \\
\hline Electricity supplied & $9(4)$ & $16(8)^{*}$ \\
\hline Electric fans owned & $4(2)$ & $14(7)^{n *}$ \\
\hline \multicolumn{3}{|l|}{ Ownership of other assets $\dagger$} \\
\hline Well & $125(58)$ & $137(69)^{*}$ \\
\hline Bicycle & $61(29)$ & $75(38)^{*}$ \\
\hline Carpet & $67(31)$ & $75(37)$ \\
\hline Radio & $121(57)$ & $131(65)$ \\
\hline Pressure cooker & $125(58)$ & $152(76)^{\cdots *}$ \\
\hline Livestock & $165(77)$ & $162(81)$ \\
\hline \multicolumn{3}{|l|}{ Land $\dagger$} \\
\hline Land owned & $115(54)$ & $126(63)$ \\
\hline Mean number of jerebs $\ddagger$ & 5.4 & $7.5^{*}$ \\
\hline Land leased to others & $16(7)$ & $25(13)$ \\
\hline Mean number of jerebs & 6.9 & $11.2^{* n}$ \\
\hline Land rented from others & $73(34)$ & $52(26)$ \\
\hline Mean number of jerebs & 3.7 & 4.6 \\
\hline Labours for others & $72(34)$ & $46(23)^{*}$ \\
\hline Supports extended family & $24(11)$ & $26(13)$ \\
\hline Employer of labourers & $29(14)$ & $50(25)^{* * *}$ \\
\hline Possesses cash reserves & $46(21)$ & $61(31)^{*}$ \\
\hline Has access to credit & $179(84)$ & $144(72)^{n+* t}$ \\
\hline
\end{tabular}

"P<0.05; ** $P<0.01 ; * * P<0.001$.

$\uparrow$ Only positive responses are shown; as households may have more than one asset/attribute column totals exceed $100 \%$.

$\ddagger 1$ hectare $=5$ jerebs.

richest quartile than to the two lowest quartiles and this likelihood increased to 4.5 when the effect of variation between districts was adjusted using the logistic model.
Although exact odds could not be ascertained, because probabilities of selection inevitably differed between net owners and non-owners, the logistic approximation indicated that for each unit increase in socio-economic status the odds of net ownership increased by 1.7 .

\section{Discussion}

More than $50 \%$ of households in this study population had a negative PCA economic index. Three key asset variables working on another person's land, renting land from others and the mean area of land rented - contributed negatively to the index. These three variables were interrelated and were potentially useful indicators of poor households. However, their association with bed net ownership was not particularly strong, and this highlights the need for an index based on several assets rather than on one or a few individual assets. The use of PCA to create an asset index appears to be a robust method for making meaningful socio-economic distinctions within populations of developing countries. It has coherence, and addresses the problem of weighing assets by allowing weights to be determined statistically. The method provides better accuracy than a system of arbitrary equal weighings, subjective weighings or multivariate regression because it requires no knowledge of prices or perceived values of assets (Filmer \& Pritchett 1998). An asset index could be useful for predicting which households are less likely to buy bed nets. However, it may have more value as a monitoring or evaluation tool for identifying project limitations or indicating socio-economic groups with lower coverage that might respond to additional targeting through subsidization or educational campaigns.

Sixty per cent of non-owners of bed nets were from the poorest or lower-middle socio-economic quartiles. Many of these said they had more pressing daily problems than mosquitoes or fevers. Their priorities were feeding and clothing the family, and while relatives and friends were willing to lend money for urgent treatment when the need arose, there was often reluctance to take loans for preventive or non-essential items such as nets (N. Howard, unpublished data). Scarcity of financial resources in conflict-affected countries, whether within governments or within families, compromises both the maintenance of health infrastructure and the ability of families to obtain the means for preventing illness. Although the current health care paradigm emphasizes individual responsibility and programmatic economic sustainability (Mills 1998), it will be necessary to find additional ways of motivating poorer households, which have more difficulty mobilizing resources, in order to increase overall coverage rates of ITN. Survey respondents described ITN as beneficial for 
N. Howard et al. Socio-economic factors associated with the purchasing of insecticide-treated nets

Table 3 Distribution of asset ownership in each socio-economic quartile. Total number of households (HH) in each quartile was 103

\begin{tabular}{|c|c|c|c|c|}
\hline Indicators & $\begin{array}{l}\text { Poorest } \\
25 \% n(\%)\end{array}$ & $\begin{array}{l}\text { Lower-middle } \\
25 \% n(\%)\end{array}$ & $\begin{array}{l}\text { Upper-middle } \\
25 \% n(\%)\end{array}$ & $\begin{array}{l}\text { Richest } \\
25 \% n(\%)\end{array}$ \\
\hline $\begin{array}{l}\text { PCA Socio-economic index } \\
\text { Household head's job }\end{array}$ & -3.4 to -1.29 & \multicolumn{2}{|c|}{ Household head's job } & $0.86-11.4$ \\
\hline Not farmer & $25(24)$ & $35(34)$ & $35(34)$ & $41(39)$ \\
\hline Mean age (years) & 45 & 44 & 45 & 44 \\
\hline \multicolumn{5}{|l|}{ Houshold Head's education } \\
\hline None & $76(74)$ & $65(63)$ & $51(49)$ & $45(43)$ \\
\hline Primary school & $11(10)$ & $4(4)$ & $7(7)$ & $6(6)$ \\
\hline Secondary school & $9(9)$ & $19(18)$ & $11(11)$ & $13(12)$ \\
\hline Higher & $7(7)$ & $15(15)$ & $34(33)$ & $41(39)$ \\
\hline \multicolumn{5}{|l|}{ Source of income* } \\
\hline One source & $77(75)$ & $75(73)$ & $72(70)$ & $72(69)$ \\
\hline Two sources & $25(25)$ & $24(23)$ & $26(25)$ & $31(29)$ \\
\hline Three sources & $1(1)$ & $4(4)$ & $5(5)$ & $2(2)$ \\
\hline \multicolumn{5}{|l|}{ House score $\dagger$} \\
\hline Zero & $42(41)$ & $15(15)$ & $8(8)$ & $0(0)$ \\
\hline One & $35(34)$ & $46(45)$ & $26(25)$ & $11(11)$ \\
\hline Two & $14(13)$ & $20(19)$ & $22(21)$ & $15(14)$ \\
\hline Three & $12(12)$ & $22(21)$ & $46(45)$ & $60(57)$ \\
\hline Four & $0(0)$ & $0(0)$ & $1(1)$ & $3(3)$ \\
\hline Five & $0(0)$ & $0(0)$ & $0(0)$ & $16(15)$ \\
\hline Mean number of rooms & 2.4 & 2.9 & 4.1 & 5.3 \\
\hline \multicolumn{5}{|l|}{ Ownership of other assets } \\
\hline Well & $44(43)$ & $66(64)$ & $68(66)$ & $84(80)$ \\
\hline Bicycle & $14(14)$ & $19(18)$ & $40(39)$ & $63(60)$ \\
\hline Carpet & $11(11)$ & $30(29)$ & $41(40)$ & $60(57)$ \\
\hline Radio & $25(24)$ & $57(55)$ & $77(74)$ & $93(89)$ \\
\hline Pressure cooker & $44(43)$ & $62(60)$ & $73(71)$ & $98(93)$ \\
\hline Livestock & $69(67)$ & $77(75)$ & $85(83)$ & $96(91)$ \\
\hline \multicolumn{5}{|l|}{ Land } \\
\hline Land owned & $19(18)$ & $49(47)$ & $74(71)$ & $99(94)$ \\
\hline Mean number of jerebs & 2.3 & 3.2 & 3.9 & 11.0 \\
\hline Land leased to others & $0(0)$ & $0(0)$ & $3(3)$ & $38(36)$ \\
\hline Mean number of jerebs & 0 & 0 & 1.0 & 10.2 \\
\hline Land rented from others & $60(58)$ & $26(25)$ & $25(24)$ & $14(13)$ \\
\hline Mean number of jerebs & 4.1 & 3.5 & 4.5 & 4.2 \\
\hline Mean no. $\mathrm{HH}$ members who are employed & 1.7 & 1.8 & 2.2 & 3.2 \\
\hline $\mathrm{HH}$ with members working on land of others & $50(49)$ & $36(35)$ & $21(20)$ & $11(10)$ \\
\hline HH supporting extended family & $4(4)$ & $6(6)$ & $13(13)$ & $27(26)$ \\
\hline Employer of labourers & $6(6)$ & $9(9)$ & $20(19)$ & $44(42)$ \\
\hline Possesses cash reserves & $23(22)$ & $25(24)$ & $24(23)$ & $35(33)$ \\
\hline Has access to credit & $91(88)$ & $79(76)$ & $78(76)$ & $75(71)$ \\
\hline
\end{tabular}

PCA, principal components analysis.

* Sources of income include: wages, crops, regular salaries, rents, animals and donations (no HH had more than three sources).

$\dagger$ House score incorporates the following assets: house owned, guest room present, guest rooms carpeted, electricity and electric fans.

those who could afford spending on prevention rather than borrowing for treatment. While it was not possible to directly estimate monthly household income, many said ITN were unaffordable even at a partially subsidized cost of US\$4 per net. But a significant minority set higher store on ITN, as evidenced by the $39 \%$ of net owning families that belonged to the lowest and lowermiddle quartiles. Thus some of the poorest may not only aspire to owning ITN but may even prioritize acquisition of ITN. 
N. Howard et al. Socio-economic factors associated with the purchasing of insecticide-treated nets

\begin{tabular}{|c|c|c|c|c|}
\hline $\begin{array}{l}\text { Socio-economic } \\
\text { quartile }\end{array}$ & $\begin{array}{l}\text { Non-owners of } \\
\text { nets } n(\%)\end{array}$ & $\begin{array}{l}\text { Owners of } \\
\text { nets } n(\%)\end{array}$ & $\begin{array}{l}\text { Crude odds ratio } \\
(95 \% \mathrm{CI})\end{array}$ & $\begin{array}{l}\text { Adjusted odds } \\
\text { ratio } \dagger(95 \% \mathrm{CI})\end{array}$ \\
\hline Poorest & $64(30)$ & $39(20)$ & 1 & 1 \\
\hline Lower-middle & $65(30)$ & $38(19)$ & $0.96(0.5-1.7)$ & $1.04(0.6-1.9)$ \\
\hline Upper-middle & $48(23)$ & $55(27)$ & $1.88(1.1-3.3)^{*}$ & $2.35(1.3-4.3)^{* *}$ \\
\hline Richest & $37(17)$ & $68(34)$ & $3.02(1.7-5.3)^{x+4 \times n}$ & $4.50(2.4-8.4)^{* 2 \times n}$ \\
\hline
\end{tabular}

Table 4 Association between socio-economic quartile and bed net ownership

"P<0.05, * $P<0.01$, ** $P<0.001$.

$\dagger$ Adjusted for the effect of variation between study districts.

Mantel-Haenszel odds ratio score test for trend $=1.48, P<0.001$.

Adjusted trend odds ratio $=1.71(1.4-2.1), P<0.001$.

High coverage is essential to achieve the public health goal of ridding malaria from a locality (Rowland $e t a l$. 2002). Some have argued for free distribution of ITN to groups who want nets but cannot afford them (Curtis 2000; Guyatt et al. 2002). If nets are distributed cost-free this may not only undermine the development of private sector delivery systems but may also encourage an expectation of continuing aid that cannot be fulfilled (Chambon et al. 1997; Rashed et al. 1999). As there appear to be no major differences between ITN owners and non-owners in terms of knowledge, experiences or perceptions, but socio-economic factors 'do' appear to have a significant influence on the decision to purchase ITN, a subsidized distribution (e.g. dual-priced or voucher-based), in accordance with socio-economic level, could be appropriate to improve coverage. It must be anticipated that without some form of subsidization, sales increases are likely to come from the richer sectors of the population. This will continue to push the burden of disease from the economically self-sufficient to the economically disadvantaged.

Despite the considerable logistic difficulties posed by subsidies for implementing agencies, a targeted but perhaps temporary subsidy does appear necessary to persuade the poorest sectors that ITN are not unattainable. Those who are able to afford but have not yet purchased ITN might be encouraged by campaigns that publicize the advantages of ownership.

\section{Acknowledgements}

We would like to express our thanks to all members of the survey team and staff of HNI Jalalabad for their help. Thanks also to Kara Hanson and Ilona Carneiro for advice on data analysis. HealthNet International's Malaria Control and Research Programme is supported by the European Commission (DG1), the United Nations High Commissioner for Refugees and WHO/UNDP/World Bank Special Programme for Research and Training in Tropical Diseases (Project no. 960662). M.R. and D.C. are supported by the UK Department for International Development and the Gates Malaria Partnership. None of these donors can accept responsibility for any information provided or views expressed.

\section{References}

Abdulla S, Armstrong-Schellenberg JRM, Nathan R et al. (2001) Impact on malaria morbidity of a programme supplying insecticide treated nets in children aged under 2 years in Tanzania: community cross sectional study. British Medical Journal $322,270-273$.

Armitage P \& Berry G (1987) Statistical Methods in Medical Research. Blackwell Science Publications, Oxford.

Bouma MJ, Parvez SD, Nesbit R et al. (1996) Malaria control using permethrin applied to tents of nomadic Afghan refugees in northern Pakistan. Bulletin of the World Health Organisation 74, 413-421.

Chambon R, Lemardeley P, Louis FJ, Foumane V, Louis JP (1997) Knowledge, attitudes and practices of populations with regard to nuisance mosquitoes: the results of six surveys carried out in Cameroon in 1994. Bulletin de la Societe de Pathologie Exotique 90, 364-369.

Chavasse D, Reed C \& Attawell K (1999) Insecticide Treated Net Projects: a Handbook for Managers. Malaria Consortium, London \& Liverpool.

Curtis C (2000) Should the Poor be Made to Pay for Insecticide Treated Nets? In Roll Back Malaria for African Prosperity. Center for International Development at Harvard University, Cambridge.

Dhir SL \& Rahim A (1957) Malaria and its control in Afghanistan (1950-1954). Indian Journal of Malariology 11, 73-126.

Filmer D \& Pritchett L (1998) Estimating Wealth Effects without Expenditure Data - or Tears: Educational Enrollment in India. Development Economics Research Group, The World Bank, Washington DC.

Filmer D \& Pritchett L (1999) The effect of household wealth on educational attainment: evidence from 35 countries. Population and Development Review 1, 85-120.

Graham K, Mohammad N, Rehman H et al. (2002a) Comparison of three pyrethroid treatments of top-sheets for malaria control in emergencies: entomological and user acceptance studies in an Afghan refugee camp in Pakistan. Medical o Veterinary Entomology 16, 199-207. 
N. Howard et al. Socio-economic factors associated with the purchasing of insecticide-treated nets

Graham K, Mohammad N, Rehman H et al. (2002b) Insecticide treated plastic tarpaulins for control of malaria vectors in refu gee camps. Medical \& Veterinary Entomology 16, 404-408.

Guyatt HL, Ochola SA \& Snow RW (2002) Too poor to pay: charging for insecticide-treated bed nets in highland Kenya. Tropical Medicine of International Health 7, 846-850.

Hewitt S, Rowland M, Nasir M et al. (1995) Pyrethroid sprayed tents for malaria control: an entomological evaluation in Pakistan's North West Frontier Province. Medical $\sigma$ Veterinary Entomology 9, 344-352.

Kolaczinski J \& Webster J (2003) Malaria control in complex emergencies: the example of East Timor. Tropical Medicine of International Health 8, 48-55.

Lariosa T (1986) Culture, environment and peoples perceptions: considerations in malaria control in the Philippines. South East Asian Journal of Tropical Medicine and Public Health 17, 360370.

Mills A (1998) Operational research on the economics of insecticide-treated mosquito nets: lessons of experience. Annals of Tropical Medicine \& Parasitology 92, 435-447.

Ongore D, Kamunvi F, Knight R et al. (1989) A study of knowledge, attitudes and practices (KAP) of a rural community on malaria and the mosquito vector. East African Medical Journal 66, 79-90.

Rab MA, Freeman TW, Durrani N et al. (2001) Resistance of Plasmodium falciparum malaria to chloroquine is widespread in eastern Afghanistan. Annals of Tropical Medicine of Parasitology 95, 591-602.

Rashed S, Johnson H, Dongier P et al. (1999) Determinants of the permethrin impregnated bednets (PIB) in the Republic of Benin: the role of women in the acquisition and utilization of PIBs. Social Science of Medicine 49, 993-1005.

Rowland M \& Nosten F (2001) Malaria epidemiology and control in refugee camps and complex emergencies. Annals of Tropical Medicine \& Parasitology 95, 645-658.
Rowland M, Bouma M, Ducornez D et al. (1996) Pyrethroid impregnated bed nets for self protection from malaria for Afghan refugees. Transactions of the Royal Society of Tropical Medicine of Hygiene 90, 357-361.

Rowland M, Hewitt S, Saleh P et al. (1997) Sustainability of pyrethroid-impregnated bednets for malaria control in Afghan communities. Bulletin of the World Health Organization 75, 23-29.

Rowland M, Durrani N, Hewitt S et al. (1999) Permethrin treated chaddars and top-sheets: appropriate technology for protection against malaria in Afghanistan and other complex emergencies. Transactions of the Royal Society of Tropical Medicine $\sigma$ Hygiene 93, 465-472.

Rowland M, Mohammed N, Rehman H et al. (2002a) Mosquito vectors and transmission of malaria in eastern Afghanistan. Transactions of the Royal Society of Tropical Medicine and Hygiene 96, 620-626.

Rowland M, Webster J, Saleh P et al. (2002b) Prevention of malaria in Afghanistan through social marketing of insecticidetreated nets: evaluation of coverage and effectiveness by crosssectional surveys and passive surveillance. Tropical Medicine $\forall$ International Health 7, 813-822.

Shah I, Rowland M, Mehmood P et al. (1997) Chloroquine resistance in Pakistan and the upsurge of falciparum malaria in Pakistani and Afghan refugee populations. Annals of Tropical Medicine of Parasitology 91, 591-602.

Toole MJ \& Waldman RJ (1997) The public health aspects of complex emergencies and refugee situations. Annual Review of Public Health 18, 283-312.

Webster J, Chandramohan D, Freeman T et al. (2003) A health facility based case-control study of effectiveness of insecticide treated nets: potential for selection bias due to pre-treatment with chloroquine. Tropical Medicine \& International Health 8, 196-201.

\section{Authors}

Natasha Howard, Tim Freeman, Ahmed Shafi, Mohammed Rafi and Sayed Enayatullah, HealthNet International, 11-A Circular Lane, PO Box 889, University Town, Peshawar, Pakistan. Fax: +92 91 840379; E-mail: NH, howardsend@hotmail.com;

TF, malairzw@yahoo.co.uk; AS, ahmad_shaf@yahoo.com; MR, all_rafi@yahoo.com; SE, sayedenayat@engineer.com

Mark Rowland (corresponding author) and Daniel Chandramohan, London School of Tropical Medicine and Hygiene, Keppel Street, London WC1E 7HT, UK. E-mail: mark.rowland@lshtm.ac.uk, daniel.chandramohan@lshtm.ac.uk 
N. Howard et al. Socio-economic factors associated with the purchasing of insecticide-treated nets

Appendix I Summary statistics of variables used in the principal components analysis model for determining socio-economic index

\begin{tabular}{|c|c|c|c|}
\hline Indicator variables & Score & Mean* (SD) $^{*}$ & Weight \\
\hline Leases land to others & 0.32632 & $0.10(0.30)$ & 1.09 \\
\hline No. of jerebs leased $\dagger$ & 0.34365 & $0.95(4.5)$ & 0.08 \\
\hline House $\neq$ & 0.28564 & $1.9(1.3)$ & 0.22 \\
\hline No, of Rooms & 0.30219 & $3.7(2.1)$ & 0.14 \\
\hline Land owned & 0.26903 & $0.58(0.49)$ & 0.55 \\
\hline No. of jerebs owned & 0.36065 & $3.8(8.9)$ & 0.04 \\
\hline Radio owned & 0.22996 & $0.61(0.49)$ & 0.47 \\
\hline Employs extra staff & 0.22227 & $0.19(0.39)$ & 0.57 \\
\hline No. of family in employment & 0.20337 & $2.2(1.8)$ & 0.11 \\
\hline Bicycle owned & 0.19646 & $0.33(0.47)$ & 0.42 \\
\hline Cooker owned & 0.19506 & $0.67(0.47)$ & 0.42 \\
\hline Household heads education level & 0.16703 & $1.0(1.3)$ & 0.13 \\
\hline Carpet owned & 0.16182 & $0.34(0.48)$ & 0.34 \\
\hline Well owned & 0.15813 & $0.64(0.48)$ & 0.33 \\
\hline Supports extended family & 0.13036 & $0.12(0.33)$ & 0.40 \\
\hline Livestock owned & 0.09780 & $0.79(0.41)$ & 0.24 \\
\hline Possesses cash reserves & 0.07350 & $0.26(0.44)$ & 0.17 \\
\hline Household head's job & 0.05187 & $0.33(0.47)$ & 0.11 \\
\hline Sources of income & 0.00158 & $1.3(0.52)$ & 0.003 \\
\hline Household head's age & -0.00571 & $45(14)$ & -0.0004 \\
\hline Availability of credit & -0.04372 & $0.78(0.42)$ & -0.10 \\
\hline Family members work land of others & -0.16097 & $0.29(0.45)$ & -0.36 \\
\hline Rents land from others & -0.16498 & $0.30(0.46)$ & -0.36 \\
\hline No. of jerebs rented4 & -0.10406 & $1.2(2.8)$ & -0.04 \\
\hline
\end{tabular}

* Means were tabulated before factorization.

$\dagger 1$ hectare $=5$ jerebs.

$\$$ House variable includes ownership, electricity availability, electric fan owned, guest room present, guest room carpeted.

If Education level includes none, primary, secondary, tertiary. 